\title{
Incidence, distribution, seasonality, and demographic risk factors of Salmonella Enteritidis human infections in Ontario, Canada, 2007-2009
}

\author{
Csaba Varga ${ }^{1,2^{*}}$, David L Pearl ${ }^{1}$, Scott A McEwen ${ }^{1}$, Jan M Sargeant ${ }^{1,3}$, Frank Pollari ${ }^{4}$ and Michele T Guerin ${ }^{1}$
}

\begin{abstract}
Background: In Canada, surveillance systems have highlighted the increasing trend of Salmonella enterica serovar Enteritidis (S. Enteritidis) human infections. Our study objectives were to evaluate the epidemiology of $S$. Enteritidis infections in Ontario using surveillance data from January 1, 2007 through December 31, 2009.

Methods: Annual age-and-sex-adjusted incidence rates (IRs), annual and mean age-adjusted sex-specific IRs, and mean age-and-sex-adjusted IRs by public health unit (PHU), were calculated for laboratory-confirmed S. Enteritidis cases across Ontario using direct standardization. Multivariable Poisson regression with PHU as a random effect was used to estimate incidence rate ratios (IRRs) of $S$. Enteritidis infections among years, seasons, age groups, and sexes.

Results: The annual age-and-sex-adjusted IR per 100,000 person-years was 4.4 [95\% Cl 4.0-4.7] in 2007, and 5.2 [95\% $\mathrm{Cl}$ 4.8-5.6] in both 2008 and 2009. The annual age-adjusted sex-specific IRs per 100,000 person-years ranged from 4.5 to 5.5 for females and 4.2 to 5.2 for males. The mean age-adjusted sex-specific IR was 5.1 [95\% Cl 4.8-5.4] for females and 4.8 [95\% Cl 4.5-5.1] for males. High mean age-and-sex-adjusted IRs (6.001-8.10) were identified in three western PHUs, one northern PHU, and in the City of Toronto. Regression results showed a higher IRR of S. Enteritidis infections in 2009 [IRR $=1.18,95 \% \mathrm{Cl} 1.06-1.32 ; \mathrm{P}=0.003]$ and 2008 [IRR $=1.17,95 \% \mathrm{Cl} 1.05-1.31 ; \mathrm{P}=0.005]$ compared to 2007. Compared to the fall season, a higher IRR of S. Enteritidis infections was observed in the spring $[\mathrm{IRR}=1.14,95 \% \mathrm{Cl} 1.01-1.29 ; \mathrm{P}=0.040]$. Children $0-4$ years of age (reference category), followed by children 5-9 years of age $[\mathrm{IRR}=0.64,95 \% \mathrm{Cl} 0.52-0.78 ; \mathrm{P}<0.001]$ had the highest IRRs. Adults $\geq 60$ years of age and $40-49$ years of age $[\mathrm{IRR}=0.31,95 \% \mathrm{Cl} 0.26-0.37 ; \mathrm{P}<0.001]$ had the lowest IRRs.

Conclusions: The study findings suggest that there was an increase in the incidence of $S$. Enteritidis infections in Ontario from 2007 to 2008-2009, and indicate seasonal, demographic, and regional differences, which warrant further public health attention.
\end{abstract}

Keywords: Salmonella enteritidis, Incidence, Poisson regression, Mixed model, Direct standardization, Demographic risk factors, Ontario, Canada

\section{Background}

Salmonellosis remains an important public health issue worldwide [1-3], causing considerable health costs [4-7] and financial losses to all members of the food supply chain [2]. Globally, non-typhoidal salmonellae (NTS) cause an estimated 93.8 million human infections and

\footnotetext{
*Correspondence: cvarga@uoguelph.ca

'Department of Population Medicine, Ontario Veterinary College, University of Guelph, Guelph, ON N1G 2W1, Canada

${ }^{2}$ Ontario Ministry of Agriculture, Food and Rural Affairs, Guelph, ON N1G 4Y2, Canada

Full list of author information is available at the end of the article
}

155,000 deaths annually [3]. Non-typhoidal salmonellae are the second most frequently reported enteric bacterial pathogens in Canada [8,9], the United States of America (US) [10], and Europe [11]; and they are the top foodborne bacteria causing hospitalization and death in Canada [12] and the US [13,14].

Salmonella enterica serovar Enteritidis (S. Enteritidis) recently became the most common serotype among the NTS in the US [10], with a significantly increased incidence in 2009 compared with the periods 2006-2008 and 1996-1998 [6,14]. Moreover, in Canada, surveillance

\section{Ciomed Central}

(c) 2013 Varga et al.; licensee BioMed Central Ltd. This is an Open Access article distributed under the terms of the Creative Commons Attribution License (http://creativecommons.org/licenses/by/2.0), which permits unrestricted use, distribution, and reproduction in any medium, provided the original work is properly cited. 
systems have highlighted the increasing trend of $S$. Enteritidis human infections, such that $S$. Enteritidis has become the most prevalent NTS serotype $[8,9,15]$. Considering the under-reporting rate of salmonellosis in Canada (an estimated 13 to 37 cases are unreported per reported case), the burden of infections is even higher [16].

The epidemiology of human $S$. Enteritidis infections is complex due to the multitude of risk factors that could be associated with illness. Previous epidemiological studies have revealed the following individual-level risk factors for $S$. Enteritidis infections: eating chicken outside of the home [17,18]; eating breaded, stuffed chicken products [19] and raw or undercooked eggs [18,20,21]; another infected person in the home [22]; eating food prepared by an infected food handler [23-26]; contact with birds and reptiles [26]; international travel [18,26-28]; young age $[29,30]$; and exposures during June and July [31]; although other risk factors might also be important.

In Canada, health regions are administrative zones demarcated by provincial ministries of health according to provincial legislations [32]. In Ontario, Canada there are 36 public health units (PHUs) that oversee health promotion and disease prevention programs. In Ontario, salmonellosis is a reportable disease under provincial legislation and all laboratory-confirmed cases are reported to the local PHU; personnel at each PHU are required to perform case investigations and enter their findings into the Ontario Ministry of Health and Long-Term Care's (MOHLTC) integrated Public Health Information System (iPHIS) surveillance database. In addition, all clinical Salmonella isolates are sent to Public Health Ontario's Toronto Public Health Laboratories for confirmation and serotyping using conventional methods [33].

Although passive surveillance systems represent an underestimation of disease burden, they provide invaluable data on enteric disease incidence and trends $[34,35]$. There is a need to better understand the demographic, geographic, and seasonal factors associated with the increase in human $S$. Enteritidis infections in Ontario and to provide evidence-based information for policy makers to prioritize future efforts in addressing the increasing number of infections. Thus, the objectives of this study were to 1) describe annual age-and-sexadjusted incidence rates (IRs), and annual and mean age-adjusted sex-specific IRs of $S$. Enteritidis cases in Ontario; 2) describe the mean age-and-sex-adjusted IR for each PHU; and 3) identify associations between $S$. Enteritidis IRs and demographic and seasonal factors.

\section{Methods}

\section{Data sources}

In Ontario, a confirmed case of salmonellosis is defined as the isolation of Salmonella (excluding Salmonella
Typhi or Paratyphi) from an appropriate clinical sample (e.g., stool, urine, blood) with or without clinically compatible signs and symptoms [36]. Data pertaining to the $S$. Enteritidis cases' age, sex, reporting PHU, and date of illness onset were acquired from the iPHIS database. The University of Guelph Ethics Review Board was consulted because our research involved human participants; however, ethics approval was not required because our data did not contain any personal or health information that could be linked back to the original identifiers. The data represent all cases of $S$. Enteritidis that were captured within the database between January 1, 2007 and December 31, 2009. Travel-related (i.e., those who had traveled outside of Canada within 3 days before the onset of illness) and outbreaks (two or more epidemiologicallylinked cases) were included in the analysis because the study objectives were to describe the overall epidemiology of $S$. Enteritidis infections in Ontario.

The Census of Canada is administered every five years by Statistics Canada, to collect demographic and socioeconomic information on Canadians [37]. Estimates based on the 2006 Census of Population for each year, age category, sex, and PHU were obtained from Statistics Canada, Demography Division [38].

\section{Statistical methods}

The distribution of values was examined, missing data and improbable values were identified, and the data were corrected wherever possible or eliminated from the analysis. Descriptive and statistical analyses were performed using Microsoft Excel 2000 (Microsoft Corporation, Redmond, WA, USA) and STATA Intercooled statistical software, version 10.1 (Stata Corporation, College Station, TX, USA).

Direct standardization [39-41] was used with the PHU-, year-, age-, and sex-based population as the reference population to calculate annual age-and-sex-adjusted IRs, and annual and mean age-adjusted sex-specific IRs for $S$. Enteritidis cases in Ontario, and the mean age-and-sexadjusted IR for each PHU.

To identify associations between $S$. Enteritidis IRs in Ontario and demographic and seasonal factors, a multivariable Poisson regression analysis was conducted. The dependent variable was the number of $S$. Enteritidis cases by year, season, age group, sex, and PHU (see Additional file 1 - Legend 1 for an example of the data structure). The categorical independent variables were year, season, age group, sex, and PHU. The variable PHU represented the 36 PHUs in Ontario. The PHU was included as a fixed effect because of the observed variability of the IRs across PHUs (Figure 1). The District of Algoma Health Unit, because it had the lowest IR, was used as the reference category to which the other PHUs were compared. The date of onset of illness reported by each $S$. Enteritidis case was used to assign the case to a particular year and season. 


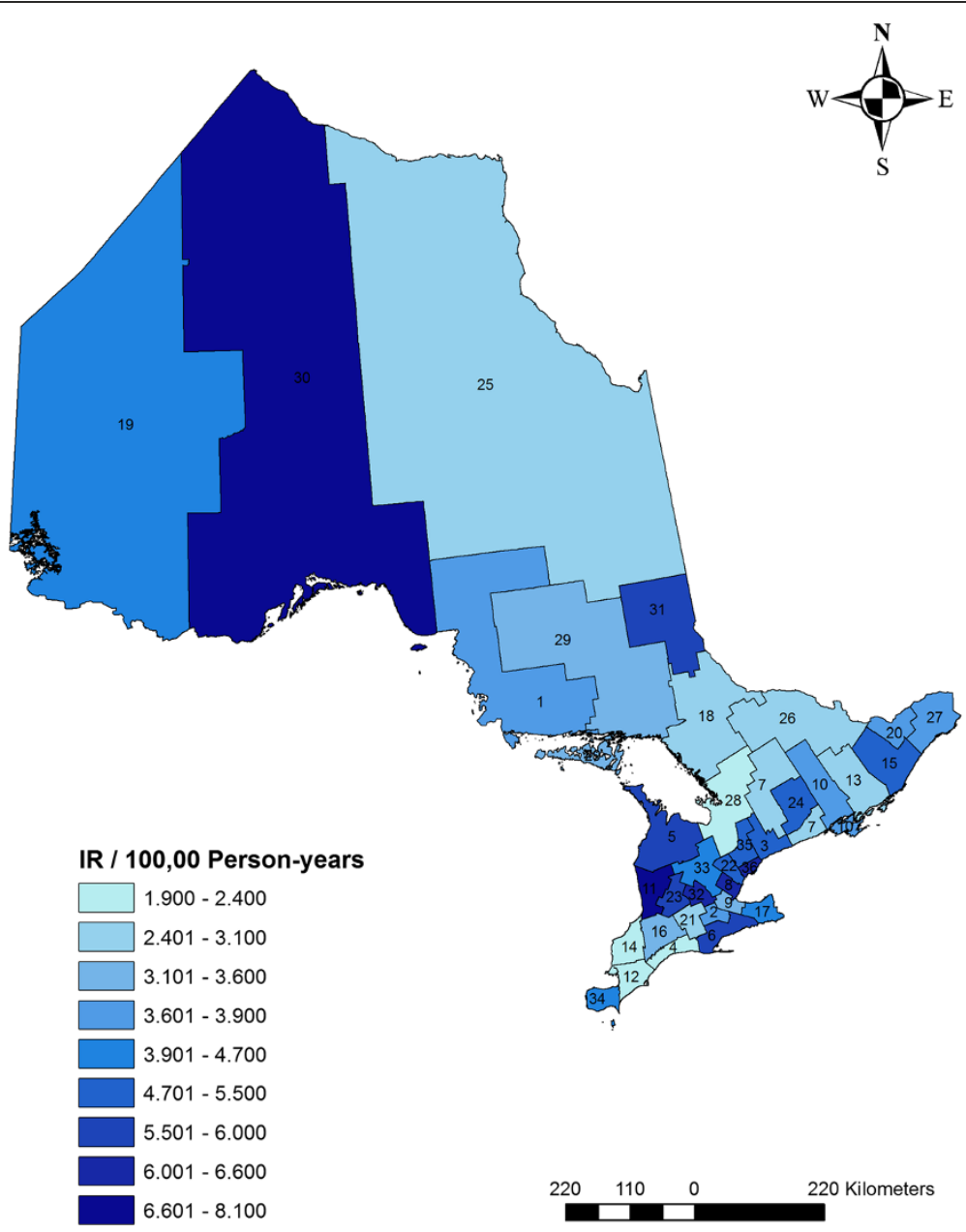

Figure 1 Mean age-and-sex-adjusted incidence rates of Salmonella Enteritidis infections, across Ontario public health units, 2007-2009 a). a) IR- Incidence rate. Public health unit labels and names are presented in Additional file 2 - Legend 2.

When the date of onset was missing, the date when the sample was received by the laboratory or when the case was reported into the iPHIS database was used. Season was categorized as winter (December, January, and February), spring (March, April, and May), summer (June, July, and August), and fall (September, October, and November). The variable year was defined as a consecutive 12-month period from January $1^{\text {st }}$ to December $31^{\text {st }}$; thus, there were three categories for year $(2007,2008$, and 2009). The variable age included ten-year age categories, with the exception of children $<4$ years of age and those 5-9 years of age, which were retained because of their biological importance $[42,43]$, and adults 60 years of age and older, which were pooled into one category because of the small number of cases in this age group. Pair-wise correlation coefficients using the Spearman's rank test among all variables were examined. If the independent variables were highly correlated (Spearman's rho $>0.70$ ), variables with the smallest $p$-value were considered for the model building process. To address the differences in year-, age group-, sex-, and PHU-based population size estimates, we used the natural logtransformed population estimates as the offset, which accounted for the denominator when calculating incidence rate ratios (IRRs). An IRR was the IR in the category of interest compared to the IR in the reference category. Variables with a p-value equal to or less than 0.05 were considered significant and were kept in the model. Incidence rate ratios and their corresponding 95\% confidence intervals were estimated. Interaction terms were created between each independent variable and tested for significance. If the interaction term was significant $(p \leq 0.05)$ it was retained in the final model. The model was evaluated by identifying influential observations (i.e. large values of Cook's distance) and outliers (i.e. large values of Pearson, deviance, or Anscombe residuals) using residual plots. The overall fit of the model was assessed using Deviance and Pearson $\chi^{2}$ goodness-of-fit tests [44].

To account for lack of fit, a multi-level mixed-effects Poisson regression model was then constructed using the xtmepoisson command in STATA [45], which uses 
adaptive Gaussian quadrature to approximate the log likelihood. The model included the same dependent and independent (year, season, age group, and sex) variables as the first model with the exception that PHU was included as a random intercept instead of a fixed effect. The structure of the multi-level model included an offset representing the natural log-transformed year-, age group-, sex-, and PHU-based population size estimates. As part of assessing model fit, we examined the normality of the best linear unbiased predictors (BLUPs) [46]. Outlier and influential observations were assessed using residual plots. Bayesian information criterion (BIC) was used to compare the fit of the two models.

ArcGIS 10 (Environmental Systems Research Institute, Inc., Redlands, CA, USA) was used to create a choropleth map for mean age-and-sex-adjusted IRs across Ontario's PHUs; Jenk's optimization classification method [47] was employed for defining the critical intervals. This method arranges data into classes based on their distribution by using an algorithm that reduces variance within groups and maximizes variance between groups.

\section{Results}

\section{Descriptive statistics and direct standardized incidence} rates

Between January 1, 2007 and December 31, 2009, 1,935 S. Enteritidis cases were reported into iPHIS in Ontario. Three cases were excluded because they lacked age or sex information. The date of onset of illness was reported for 1,670 (86.4\%) cases; 230 (11.9\%) and 32 (1.7\%) cases only had information on the date when the sample was received by the laboratory and the date when the case was reported into the iPHIS database, respectively. The iPHIS collects all reportable diseases throughout Ontario's PHUs, and no major changes in salmonellosis reporting requirements or testing protocols were noted during the study period, which makes our data robust and reliable. Information on specimen type was not available; however, based on our working experience at the MOHLTC, and the literature, the majority of specimens were stool samples. No major outbreaks were declared during the study period.

The age of cases ranged from $<1$ year to $>90$ years. Children $<4$ years of age and adults $\geq 60$ years of age represented $13.1 \%$ and $13.6 \%$ of cases, respectively, while adults 20-29 years of age represented $16.8 \%$ of cases. Overall, $51.6 \%$ and $48.4 \%$ of cases were females and males, respectively.

The annual age-and-sex-adjusted IR per 100,000 personyears was 4.4 [95\% CI 4.0-4.7] in 2007, and 5.2 [95\% CI 4.8-5.6] in both 2008 and 2009 (Table 1). Over the study period, the annual age-adjusted sex-specific IR per 100,000 person-years ranged between 4.5 and 5.5 for females and between 4.2 and 5.2 for males (Table 1). The mean
Table 1 Direct standardized incidence rates of Salmonella Enteritidis infections in Ontario, 2007-2009 ( $n=1,932$ cases)

\begin{tabular}{|c|c|c|c|c|}
\hline Year $^{\text {a) }}$ & & $N^{b)}$ & $\mathrm{IR}^{\mathrm{c})}$ & $95 \% \mathrm{Cl}^{\text {d) }}$ \\
\hline $2007^{\text {e) }}$ & & $12,792,937$ & 4.4 & $4.0-4.7$ \\
\hline $2008^{\text {e) }}$ & & $13,070,584$ & 5.2 & $4.8-5.6$ \\
\hline $2009^{\text {e) }}$ & & $13,064,900$ & 5.2 & $4.9-5.6$ \\
\hline \multirow[t]{2}{*}{$2007^{f)}$} & Female & $6,480,556$ & 4.5 & $4.0-5.1$ \\
\hline & Male & $6,312,381$ & 4.2 & $3.7-4.7$ \\
\hline \multirow[t]{2}{*}{$2008^{f)}$} & Female & $6,565,166$ & 5.2 & $4.7-5.8$ \\
\hline & Male & $6,505,418$ & 5.2 & $4.7-5.8$ \\
\hline \multirow[t]{2}{*}{$2009^{f)}$} & Female & $6,625,568$ & 5.5 & $5.0-6.1$ \\
\hline & Male & $6,439,332$ & 5.0 & $4.5-5.6$ \\
\hline \multirow[t]{2}{*}{ 2007-2009 9) } & Female & $19,671,290$ & 5.1 & $4.8-5.4$ \\
\hline & Male & $19,257,131$ & 4.8 & $4.5-5.1$ \\
\hline
\end{tabular}

a) Year: A consecutive 12-month period from January $1^{\text {st }}$ to December $31^{\text {st }}$.

b) N: Reference population estimates obtained from the 2006 Census of Canada.

c) IR: Direct standardized incidence rate per 100,000 person-years. Denominator included year-, age-, sex-, and public health unit-based population estimates.

d) $\mathrm{Cl}$ : Confidence interval of the adjusted IR.

e) Annual age-and-sex-adjusted IR.

f) Annual age-adjusted sex-specific IR.

g) Mean age-adjusted sex-specific IR.

age-adjusted sex-specific IR per 100,000 person-years was 5.1 [95\% CI 4.8-5.4] for females and 4.8 [95\% CI 4.5-5.1] for males (Table 1).

Seasonal counts ranged from 135 to 187 cases in winter ( mean over 3 -year period $=160$ cases), 155 to 189 in spring $($ mean $=173), 156$ to 166 in summer $($ mean $=160)$, and 121 to 177 in fall $($ mean $=151)$ (Figure 2$)$. The highest monthly count was 75 cases in March 2007 and the lowest was 28 cases in November 2007 (Figure 3).

The mean age-and-sex-adjusted IRs for the entire study period across Ontario's PHUs ranged from 1.9 to 8.1 (Figure 1; Additional file 2 - Legend 2). Visually exploring the map, the highest IRs (> 6.0 per 100,000 person-years) were observed in three south-western PHUs (Halton Regional Health Unit, Huron County Health Unit, and Waterloo Health Unit), one northern PHU (Thunder Bay District Health Unit), and in the City of Toronto Health Unit.

\section{Poisson regression}

The Deviance and Pearson $\chi^{2}$ goodness-of-fit test statistics for the Poisson model were 6,212.6 $(\mathrm{P}=1.00)$ and $17,727.6$ ( $\mathrm{P}=0.004)$, respectively. Several outlier and influential observations were identified; however, rerunning the model without these observations did not change any of the coefficients. The BIC for the model was 9,906.4.

Because one of the two goodness-of-fit tests for the Poisson model indicated lack of fit, we used a multi-level model. No outlier or influential observations were identified 


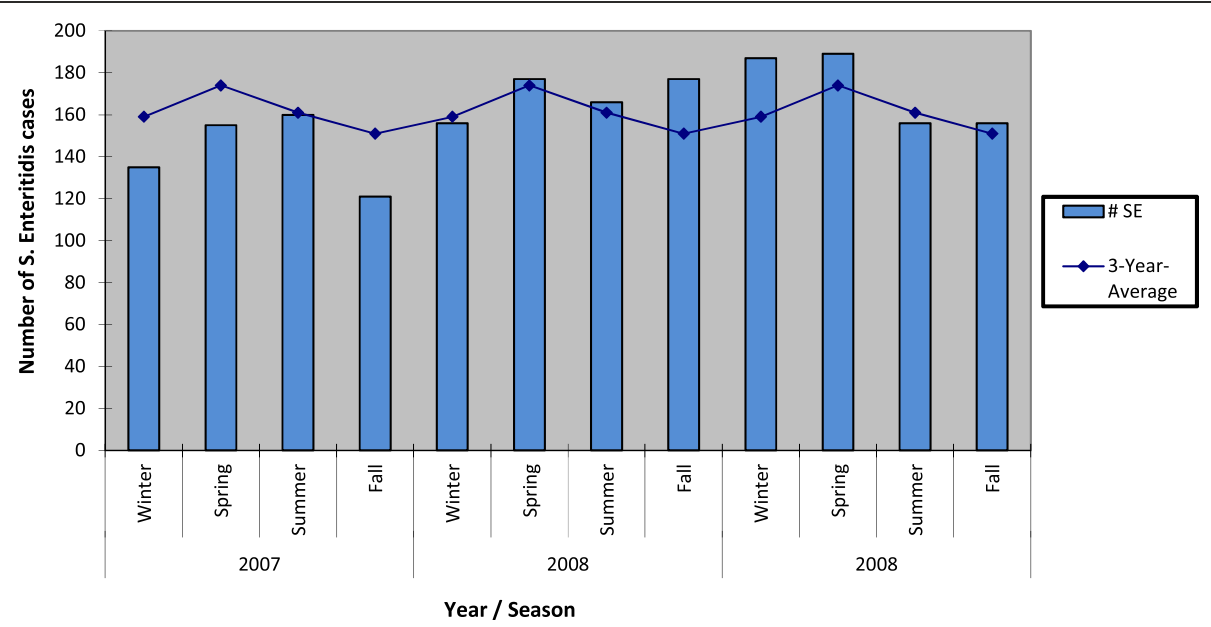

Figure 2 Seasonal distribution of Salmonella Enteritidis (S. Enteritidis) cases in Ontario, 2007-2009 ( $\mathbf{n}=\mathbf{1 , 9 3 2 )}{ }^{\text {a) }}$. a) Winter (December, January, and February), spring (March, April, and May), summer (June, July, and August), and fall (September, October, and November). Three-yearaverage: number of $S$. Enteritidis cases for each season divided by the number of years.

for the upper level residuals of the multi-level model. The BLUPs for the PHU random intercept were normally distributed. The BIC for the multi-level model was 9,655.2, indicating a better fit.

The results of the multi-level model are shown in Table 2. Significantly higher IRRs of $S$. Enteritidis infections were reported in 2009 [IRR $=1.18,95 \%$ CI 1.06 1.32] and 2008 [IRR $=1.17,95 \%$ CI 1.05-1.31] compared to 2007. Compared to the fall season, a significantly higher IRR of $S$. Enteritidis infections was reported in the spring $[\operatorname{IRR}=1.14,95 \%$ CI 1.01-1.29]. Children 0-4 years of age (reference category), followed by children 5-9 years of age $[$ IRR $=0.64,95 \%$ CI $0.52-0.78]$ had the highest IRRs of infection. Adults $\geq 60$ years of age and 40-49 years of age [IRR $=0.31,95 \%$ CI $0.26-0.37$ ] had the lowest
IRRs of infection. No statistically significant difference in $S$. Enteritidis infection rates were detected between sexes.

\section{Discussion}

Our study is the most current and geographically diverse investigation from Ontario, and fills information gaps related to current knowledge of the incidence, demographic determinants, distribution, and seasonality of human $S$. Enteritidis infections.

From 2007 to 2008-2009, an increase in annual ageand-sex-adjusted IRs of $S$. Enteritidis infections was identified. Moreover, the Poisson regression model revealed a significantly higher IRRs of $S$. Enteritidis infections in 2008 and 2009 compared to 2007. This finding is in agreement with the results of current Canadian [15]

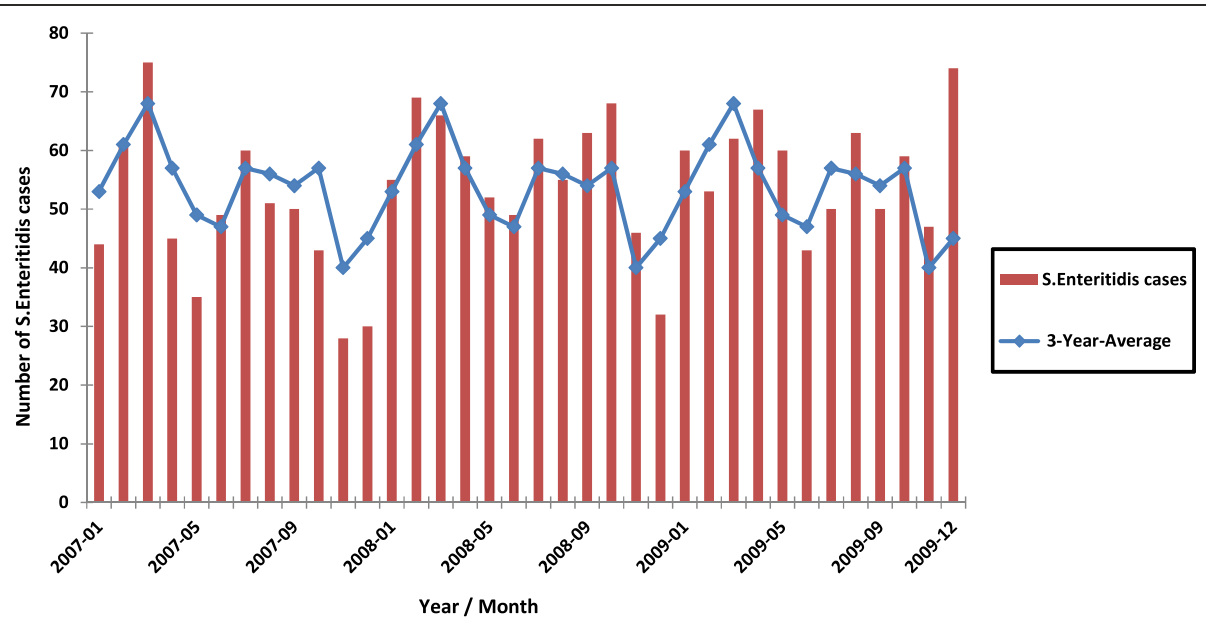

Figure 3 Number of Salmonella Enteritidis (S. Enteritidis) cases by month in Ontario, 2007-2009 $(\mathbf{n}=1,932){ }^{\text {a) }}$. ${ }^{\text {a) }}$ Three-year-average: number of Salmonella Enteritidis cases for each month divided by the number of years. 
Table 2 Risk factors for Salmonella Enteritidis infections in humans, Ontario, Canada, 2007-2009 ( $n=1,932$ cases)

\begin{tabular}{|c|c|c|c|c|}
\hline Variable $^{\text {a) }}$ & & IRR $^{\text {b) }}$ & $95 \% \mathrm{Cl}^{c)}$ & P-value ${ }^{d)}$ \\
\hline \multirow[t]{3}{*}{ Year } & 2007 & Reference & - & - \\
\hline & 2008 & 1.17 & $1.05-1.31$ & 0.005 \\
\hline & 2009 & 1.18 & $1.06-1.32$ & 0.003 \\
\hline \multirow[t]{4}{*}{ Season } & Fall & Reference & - & - \\
\hline & Spring & 1.14 & $1.01-1.29$ & 0.040 \\
\hline & Summer & 1.06 & $0.93-1.20$ & 0.377 \\
\hline & Winter & 1.06 & $0.93-1.20$ & 0.413 \\
\hline \multirow[t]{8}{*}{ Age (years) } & $0-4$ & Reference & - & - \\
\hline & $5-9$ & 0.64 & $0.52-0.78$ & $<0.001$ \\
\hline & $10-19$ & 0.44 & $0.34-0.51$ & $<0.001$ \\
\hline & $20-29$ & 0.51 & $0.43-0.60$ & $<0.001$ \\
\hline & $30-39$ & 0.34 & $0.28-0.40$ & $<0.001$ \\
\hline & $40-49$ & 0.31 & $0.26-0.37$ & $<0.001$ \\
\hline & $50-59$ & 0.33 & $0.28-0.40$ & $<0.001$ \\
\hline & $\geq 60$ & 0.31 & $0.26-0.37$ & $<0.001$ \\
\hline \multirow[t]{2}{*}{ Sex } & Female & Reference & - & - \\
\hline & Male & 0.95 & $0.87-1.04$ & 0.273 \\
\hline Intercept & & 0.00002 & $0.00002-0.00003$ & $<0.001$ \\
\hline
\end{tabular}

a) Multi-level mixed-effects Poisson regression model using adaptive Gaussian quadrature. Public health unit (PHU) was included as a random intercept. Variance of PHU random effects $=0.074[95 \% \mathrm{Cl}=0.036-0.153]$. Dependent variable: number of Salmonella Enteritidis cases by year, season, age group, sex, and PHU. Offset: natural log-transformed year-, age group-, sex-, and PHUbased population size estimates. ${ }^{\text {b) }}$ IRR: Incidence rate ratio for categorical independent variables, in which the incidence rate (IR) in the category of interest was compared to the IR in the reference category. ${ }^{\mathrm{C})} \mathrm{Cl}$ : Confidence interval of the IRR. ${ }^{\text {d) }}$ Statistically significant at $P \leq 0.05$.

and US [6] surveillance that have shown an increase in $S$. Enteritidis infections. Salmonella Enteritidis continues to be a key cause of human enteric illness and poses a substantial health burden to the North American population [3]. Reducing the incidence of $S$. Enteritidis infections is challenging due to the variety of transmission routes and contaminated food sources [26], the possible increase in environmental reservoir(s), and changes in food processing and safety practices [48]; however, increased efforts should be directed toward mitigation strategies for this pathogen.

Our study demonstrated that young children $0-4$ years of age had the highest $S$. Enteritidis infection IRRs, which is in agreement with results of other studies from developed countries $[29,30,42,49,50]$. Previous studies identified several risk factors for $S$. Enteritidis infections for this age group, including international travel $[51,52]$, riding in shopping carts and exposure to raw meat and poultry products [53], and contact with reptiles [43,52,54] and cats [43]. In our study, adults 60 years of age and older had the lowest IRR among all age groups, which is in contrast with other studies $[29,55]$. This finding was unexpected because typically the two age group extremes have the highest rates of enteric infections. Prospective research studies are needed in Ontario to assess differences in $S$. Enteritidis infection rates between age groups that are attributed to various exposures.

Examination of seasonal differences in $S$. Enteritidis rates in our study revealed a higher IRR of infections during the spring (March through May). The higher incidence in spring might be associated with international travel. Travel has been identified as an important risk factor for $S$. Enteritidis, and it was shown in recent Ontario studies that a large proportion of $S$. Enteritidis cases, especially in the winter and spring, were travelrelated $[28,56]$.

We did not find a statistically significant difference in the IRR of $S$. Enteritidis infections between females and males, which is consistent with a previous US study [29].

When analyzing the differences in the incidence rates of $S$. Enteritidis infections among Ontario's PHUs, we calculated mean age-and-sex-adjusted IRs using direct standardization. This method is useful when the prevalence of exposures might differ among age groups, sexes, and PHUs. We used geographic information system software to create choropleth maps for IRs of $S$. Enteritidis infections across PHUs in Ontario. This is a useful technique to visualize the findings of conventional statistical analysis, and by using Jenk's optimization classification for defining the critical intervals for mapping the IRs, it allowed us to identify high risk PHUs. Future research studies should be conducted to identify and assess novel transmission routes, spatio-temporal trends, and socioeconomic status indicators that might have an impact on the emergence of $S$. Enteritidis infections in these regions.

Before extrapolating our results to the whole Ontario population, a few limitations need to be noted. It is essential to mention that laboratory surveillance systems generally underestimate the true burden of enteric diseases in a population for several reasons. There might be differences in underreporting across age groups, because children and older adults are more likely to visit a physician, and physicians are more likely to request stool samples from them for testing. Moreover, there might be geographic variation in underreporting of $S$. Enteritidis infections due to differences in health care providers' accessibility, and in the sensitivity of laboratory methods used at different laboratories [34,35,57]. Finally, misclassification of cases might have occurred when cases were categorized into year and season. However this bias was likely minor because the majority of cases had date of illness onset (or date of sample reception) information. The difference between date of illness onset and the date when the samples were received by the laboratory could be estimated to be a maximum of one week, 
considering the time of delivery of samples within Ontario, and the incubation period of $S$. Enteritidis that ranges from half to three days [58].

\section{Conclusions}

Our results showed higher IRRs of $S$. Enteritidis infections in 2008 and 2009 compared to 2007, and indicate seasonal and regional differences, with a higher IRR of $S$. Enteritidis infections in the spring. In Ontario, we found that children 0-4 years of age were at the highest risk for $S$. Enteritidis infections. These results provide evidence-based information that will assist policy makers to prioritize future efforts in addressing the increase in the number of $S$. Enteritidis infections in the human population in Ontario. We recommend that children, and PHUs with high $S$. Enteritidis rates, be targeted for prevention and control programs designed to decrease the incidence of $S$. Enteritidis. Further case-control and ecological studies are needed to identify novel risk factors (food sources, socioeconomic determinants, and transmission routes) and spatio-temporal trends for $S$. Enteritidis infections in Ontario.

\section{Additional files}

Additional file 1: Legend 1. Example of data structure.

Additional file 2: Legend 2 for Figure 1. Ontario Public Health Units labels and names.

\section{Abbreviations}

BIC: Bayesian information criterion; BLUP: best linear unbiased predictor; iPHIS: integrated Public Health Information System; IR: incidence rate; IRR: incidence rate ratio; MOHLTC: Ontario Ministry of Health and Long-Term Care; NTS: non-typhoidal salmonellae; PHU: Public Health Unit; S. Enteritidis: Salmonella enterica serovar Enteritidis; US: United States of America.

\section{Competing interests}

The authors declare that they have no competing interests.

\section{Authors' contributions}

CV developed the study design, analyzed the data, interpreted results, wrote the first draft of the manuscript, responded to editorial comments, and prepared the final manuscript for submission. MTG and DLP were consulted for study design, data analysis, and interpretation of results, and reviewed and commented on manuscript drafts. SAM, FP and JMS provided advice on data analysis, interpretation of results, and reviewed and commented on manuscript drafts. All authors read and approved the final manuscript.

\section{Acknowledgements}

The authors acknowledge the MOHLTC for providing the data. We thank the staff of all PHUs and public health laboratories that tested samples, followed up with cases, and entered information into the public health surveillance database. The views expressed in this study are the views of the authors and do not necessarily reflect those of the MOHLTC.

\section{Author details}

'Department of Population Medicine, Ontario Veterinary College, University of Guelph, Guelph, ON N1G 2W1, Canada. ${ }^{2}$ Ontario Ministry of Agriculture, Food and Rural Affairs, Guelph, ON N1G 4Y2, Canada. ${ }^{3}$ Centre for Public Health and Zoonoses, Ontario Veterinary College, University of Guelph,
Guelph, ON N1G 2W1, Canada. ${ }^{4}$ Centre for Foodborne, Environmental and Zoonotic Infectious Diseases, Public Health Agency of Canada, Guelph, ON $\mathrm{N} 1 \mathrm{H}$ 8J1, Canada.

Received: 14 August 2012 Accepted: 8 May 2013

Published: 10 May 2013

\section{References}

1. Verge P, Cloeckaert A, Barrow P: Emergence of Salmonella epidemics: the problems related to Salmonella enterica serotype Enteritidis and multiple antibiotic resistance in other major serotypes. Vet Res 2005, 26:267-288.

2. Cardoen S, Van Huffel X, Berkvens D, Quoilin S, Ducoffre G, Saegerman C, Speybroeck N, Imberechts H, Herman L, Ducatelle R, Dierick K: Evidencebased semiquantitative methodology for prioritization of foodborne zoonoses. Foodborne Pathog Dis 2009, 6(9):1083-1096.

3. Majowicz SE, Musto J, Scallan E, Angulo FJ, Kirk M, O'Brien SJ, Jones TF, Fazil A, Hoekstra RM: International Collaboration on Enteric Disease 'Burden of Illness' Studies: The global burden of nontyphoidal Salmonella gastroenteritis. Clin Infect Dis 2010, 50(6):882-889.

4. Todd EC: Preliminary estimates of costs of foodborne disease in Canada and costs to reduce salmonellosis. J Food Prot 1989, 52:586-594.

5. Henson SJ, Majowicz SE, Masakure O, Sockett PN, MacDougall L, Edge VL, Thomas MK, Fyfe M, Kovacs SJ, Jones AQ: Estimation of the costs of acute gastrointestinal illness in British Columbia, Canada. Int J Food Microbiol 2008, 127(1-2):43-52.

6. Centers for Disease Control and Prevention (CDC): Vital signs: incidence and trends of infection with pathogens transmitted commonly through food--foodborne diseases active surveillance network, 10 U.S. sites, 1996-2010. MMWR Morb Mortal Wkly Rep 2011, 60(22):55-749.

7. Santos AC, Roberts JA, Cook AJ, Simons R, Sheehan R, Lane C, Adak GK, Clifton-Hadley FA, Rodrigues LC: Salmonella Typhimurium and Salmonella Enteritidis in England: costs to patients, their families, and primary and community health services of the NHS. Epidemiol Infect 2011, 139(5):742-753.

8. Public Health Agency of Canada (PHAC): National Enteric Surveillance Program. Annual Summary of Laboratory Surveillance Data for Enteric Pathogens in Canada, 2009. 2009. Available at: http://www.nml-Inm.gc.ca/ NESP_PNSME/assets/pdf/NESP 2009 Annual_Report_ENG.pdf.

9. Public Health Agency of Canada (PHAC): C-EnterNet 2008 Annual Report. 2008. Available at: http://www.phac-aspc.gc.ca/c-enternet/pubs/2008/index-eng.php.

10. Centers for Disease Control and Prevention: National Salmonella Surveillance Data: Salmonella Annual Summary Tables 2009. Atlanta, GA: U.S. Department of Health and Human Services, CDC; 2008. Available at: http://www.cdc.gov/ ncezid/dfwed/PDFs/SalmonellaAnnualSummaryTables2009.pdf.

11. European Food Safety Authority (EFSA): The community summary report on trends and sources of zoonoses, zoonotic agents, antimicrobial resistance and foodborne outbreaks in the European Union in 2006. EFSA J 2007, 130 Available at: http://www.efsa.europa.eu/en/scdocs/scdoc/130r.htm.

12. Ruzante JM, Majowicz SE, Fazil A, Davidson VJ: Hospitalization and deaths for select enteric illnesses and associated sequelae in Canada, 2001-2004. Epidemiol Infect 2011, 139(6):937-945.

13. Barton Behravesh C, Jones TF, Vugia DJ, Long C, Marcus R, Smith K, Thomas S, Zansky S, Fullerton KE, Henao OL, Scallan E: FoodNet Working Group: Deaths associated with bacterial pathogens transmitted commonly through food: foodborne diseases active surveillance network (FoodNet), 1996-2005. J Infect Dis 2011, 204(2):263-267.

14. Scallan E, Hoekstra RM, Angulo FJ, Tauxe RV, Widdowson MA, Roy SL, Jones JL, Griffin PM: Foodborne illness acquired in the United States-major pathogens. Emerg Infect Dis 2011, 17(1):7-15.

15. Nesbitt A, Ravel A, Murray R, McCormick R, Savelli C, Finley R, Parmley J, Agunos A, Majowicz SE, Gilmour M, the Canadian Integrated Program for Antimicrobial Resistance Surveillance Public Health Partnership, the Canadian Public Health Laboratory Network: Integrated surveillance and potential sources of Salmonella Enteritidis in human cases in Canada from 2003 to 2009. Epidemiol Infect 2012, 140(10):1757-1772.

16. Thomas MK, Majowicz SE, Sockett PN, Fazil A, Pollari F, Doré K, Flint JA, Edge VL: Estimated numbers of community cases of illness due to Salmonella, Campylobacter and verotoxigenic Escherichia coli: pathogen-specific community rates. Can J Infect Dis Med Microbiol 2006, 17:229-234.

17. Kimura AC, Reddy V, Marcus R, Cieslak PR, Mohle-Boetani JC, Kassenborg $H D$, Segler SD, Hardnett FP, Barrett T, Swerdlow DL: Chicken consumption is a newly identified risk factor for sporadic Salmonella enterica serotype 
Enteritidis infections in the United States: a case-control study in FoodNet sites. Emerging Infections Program FoodNet Working Group. Clin Infect Dis 2004, 38(3):52-244.

18. Voetsch AC, Poole C, Hedberg CW, Hoekstra RM, Ryder RW, Weber DJ, Angulo FJ: Analysis of the FoodNet case-control study of sporadic Salmonella serotype Enteritidis infections using persons infected with other Salmonella serotypes as the comparison group. Epidemiol Infect 2009, 137(3):408-416.

19. Smith KE, Medus C, Meyer SD, Boxrud DJ, Leano F, Hedberg CW, Elfering K, Braymen C, Bender JB, Danila RN: Outbreaks of salmonellosis in Minnesota (1998 through 2006) associated with frozen, microwaveable, breaded, stuffed chicken products. J Food Prot 2008, 71(10):2153-2160.

20. Doorduyn Y, Van Den Brandhof WE, Van Duynhoven YT, Wannet WJ, Van Pelt W: Risk factors for Salmonella Enteritidis and Typhimurium (DT104 and non-DT104) infections in The Netherlands: predominant roles for raw eggs in Enteritidis and sandboxes in Typhimurium infections. Epidemiol Infect 2006, 134(3):617-626.

21. Kuehn BM: Salmonella cases traced to egg producers: findings trigger recall of more than 500 million eggs. JAMA 2010, 304(12):1316.

22. Ethelberg S, Olsen KE, Gerner-Smidt P, Mølbak K: Household outbreaks among culture-confirmed cases of bacterial gastrointestinal disease. Am J Epidemiol 2004, 159(4):406-412.

23. Beatty ME, Shevick G, Shupe-Ricksecker K, Bannister E, Tulu A, Lancaster K, Alexander N, Zellner DE, Lyszkowicz E, Braden CR: Large Salmonella Enteritidis outbreak with prolonged transmission attributed to an infected food handler, Texas, 2002. Epidemiol Infect 2009, 137(3):417-427.

24. Hedican E, Hooker C, Jenkins T, Medus C, Jawahir S, Leano F, Smith K: Restaurant Salmonella Enteritidis outbreak associated with an asymptomatic infected food worker. J Food Prot 2009, 72(11):2332-2336.

25. Medus C, Smith KE, Bender JB, Leano F, Hedberg CW: Salmonella infections in food workers identified through routine Public Health Surveillance in Minnesota: impact on outbreak recognition. J Food Prot 2010, 73(11):2053-2058.

26. Marcus R, Varma JK, Medus C, Boothe EJ, Anderson BJ, Crume T, Fullerton KE, Moore MR, White PL, Lyszkowicz E, Voetsch AC, Angulo FJ: Emerging Infections Program FoodNet Working Group: Re-assessment of risk factors for sporadic Salmonella serotype Enteritidis infections: a case-control study in five FoodNet Sites, 2002-2003. Epidemiol Infect 2007, 135(1):84-92.

27. Johnson LR, Gould LH, Dunn JR, Berkelman R, Mahon BE: Foodnet Travel Working Group: Salmonella Infections Associated with International Travel: A Foodborne Diseases Active Surveillance Network (FoodNet) Study. Foodborne Pathog Dis 2011, 8(9):1031-1037.

28. Tighe MK, Savage R, Vrbova $L$, Toolan M, Whitfield $Y$, Varga $C$, Lee $B$, Allen $V$, Maki A, Walton R, Johnson C, Dhar B, Ahmed R, Crowcroft NS, Middleton D: The epidemiology of travel-related Salmonella Enteritidis in Ontario, Canada, 2010-2011. BMC Public Health 2012, 12(1):310.

29. Younus M, Wilkins MJ, Arshad MM, Rahbar MH, Saeed AM: Demographic risk factors and incidence of Salmonella Enteritidis infection in Michigan. Foodborne Pathog Dis 2006, 3(3):266-273.

30. Arshad MM, Wilkins MJ, Downes FP, Rahbar MH, Erskine RJ, Boulton ML, Saeed AM: A registry-based study on the association between human salmonellosis and routinely collected parameters in Michigan, 1995-2001. Foodborne Pathog Dis 2007, 4(1):16-25

31. Ravel A, Smolina E, Sargeant JM, Cook A, Marshall B, Fleury MD, Pollari F Seasonality in human salmonellosis: assessment of human activities and chicken contamination as driving factors. Foodborne Pathog Dis 2010, 7(7):785-794.

32. Government of Ontario: Health Protection and Promotion Act. Revised Statutes of Ontario. 1990.

33. Popoff MY, LeMinor L: Antigenic formulas of the Salmonella serovars. In World Health Organization Collaborating Centre for Reference and Research on Salmonella. 6th edition. Paris, France: Pasteur Institute; 1997.

34. Scallan E, Jones TF, Cronquist A, Thomas S, Frenzen P, Hoefer D, Medus C, Angulo FJ: FoodNet Working Group: Factors associated with seeking medical care and submitting a stool sample in estimating the burden of foodborne illness. Foodborne Pathog Dis 2006, 3(4):432-438.

35. MacDougall L, Majowicz S, Doré K, Flint J, Thomas K, Kovacs S, Sockett P. Under-reporting of infectious gastrointestinal illness in British Columbia, Canada: who is counted in provincial communicable disease statistics? Epidemiol Infect 2008, 136(2):248-256.

36. Ontario Ministry of Health and Long-Term Care (MOHLTC): Ontario Public Health Standards. Infectious Diseases Protocol. 2009. Available at: http://www. health.gov.on.ca/english/providers/program/pubhealth/oph_standards/ ophs/infdispro.html.

37. Statistics Canada: Census Dictionary: Census Year 2006. Catalogue no. 92-566-X. Ottawa; 2006. Available at: www12.statcan.gc.ca/census-recensement/2006/ref/ dict/pdf/92-566-eng.pdf.

38. Statistics Canada: Table 109-5325 - Estimates of population (2006 Census and administrative data), by age group and gender, Canada, provinces, territories, health regions (2011 boundaries) and peer groups, annual (number), CANSIM (database). 2011. Available at: http://www5.statcan.gc.ca/cansim/a01?lang=eng.

39. Kahn HA, Sempos CT: Statistical Methods in Epidemiology. New York: Oxford University Press; 1989.

40. Curtin LR, Klein RJ: Direct Standardization (Age-Adjusted Death Rates). Healthy People: Centres for Disease Control and Prevention; 1995:6.

41. Ahmad OB, Boschi-Pinto C, Lopez AD, Murray CJL, Lozano R, Inoue M: Age standardization of rates: a new WHO world standard. (GPE Discussion Paper No. 31. EIP/GPE/EBD). Geneva: World Health Organization; 2000.

42. Keegan VA, Majowicz SE, Pearl DL, Marshall BJ, Sittler N, Knowles L, Wilson JB: Epidemiology of enteric disease in C-EnterNet's pilot site - Waterloo region, Ontario, 1990 to 2004. Can J Infect Dis Med Microbiol 2009, 20(3):79-87.

43. Younus M, Wilkins MJ, Davies HD, Rahbar MH, Funk J, Nguyen C, Siddiqi AE, Cho S, Saeed AM: The role of exposures to animals and other risk factors in sporadic, non-typhoidal Salmonella infections in Michigan children. Zoonoses Public Health 2010, 57(7-8):e170-e176.

44. Cameron AC, Trivedi PK: Regression Analysis of Count Data. New York: Cambridge Press; 1998

45. Rabe-Hesketh S, Skrondal A: Multilevel and Longitudinal Modeling Using Stata. 2nd edition. College Station, Texas: Stata Press; 2008.

46. Robinson GK: "That BLUP is a Good Thing: The Estimation of Random Effects". Statist Sci 1991, 6(1):15-32.

47. Jenks GF: "The Data Model Concept in Statistical Mapping", International Yearbook of Cartography 7. 1967, 186-190.

48. Signs RJ, Darcey VL, Carney TA, Evans AA, Quinlan JJ: Retail food safety risks for populations of different races, ethnicities, and income levels. J Food Prot 2011, 74(10):1717-1723.

49. Zaidenstein R, Peretz C, Nissan I, Reisfeld A, Yaron S, Agmon V, Weinberger M: The epidemiology of extraintestinal non-typhoid Salmonella in Israel: the effects of patients' age and sex. Eur J Clin Microbiol Infect Dis 2010, 29(9):1103-1109.

50. Lal A, Baker MG, French NP, Dufour M, Hales S: The epidemiology of human salmonellosis in New Zealand, 1997-2008. Epidemiol Infect 2011, 30:1-10.

51. Ekdahl K, de Jong B, Wollin R, Andersson Y: Travel-associated nontyphoidal salmonellosis: geographical and seasonal differences and serotype distribution. Clin Microbiol Infect 2005, 11(2):138-144.

52. Cellucci T, Seabrook JA, Chagla Y, Bannister SL, Salvadori MI: A 10-year retrospective review of Salmonella infections at the Children's Hospital in London, Ontario. Can J Infect Dis Med Microbiol 2010, 21(2):78-82.

53. Patrick ME, Mahon BE, Zansky SM, Hurd S, Scallan E: Riding in shopping carts and exposure to raw meat and poultry products: prevalence of, and factors associated with, this risk factor for salmonella and campylobacter infection in children younger than 3 years. $J$ Food Prot 2010, 73(6):1097-1100

54. Aiken AM, Lane C, Adak GK: Risk of Salmonella infection with exposure to reptiles in England, 2004-2007. Euro Surveill 2010, 15(22):19581.

55. Majowicz SE, Doré K, Flint JA, Edge VL, Read S, Buffett MC, McEwen S, McNab WB, Stacey D, Sockett P, Wilson JB: Magnitude and distribution of acute, self-reported gastrointestinal illness in a Canadian community. Epidemiol Infect 2004, 132(4):607-617.

56. Ravel A, Nesbitt A, Marshall B, Sittler N, Pollari F: Description and burden of travel-related cases caused by enteropathogens reported in a Canadian community. Journal of Travel Medicine 2011, 18(1):8-19.

57. Edge VL, Odoi A, Fyfe M, MacDougall L, Majowicz SE, Doré K, Flint JA, Boom N, Muchaal PK, Sockett PN: Physician diagnostic and reporting practices for gastrointestinal illnesses in three health regions of British Columbia. Can J Public Health 2007, 98(4):306-310.

58. Heymann DL: Control of communicable diseases manual: an official report of the American Public Health Association. 19th edition. Washington, DC American Public Health Association; 2008.

doi:10.1186/1471-2334-13-212

Cite this article as: Varga et al.: Incidence, distribution, seasonality, and demographic risk factors of Salmonella Enteritidis human infections in Ontario, Canada, 2007-2009. BMC Infectious Diseases 2013 13:212. 